structed. Many patients take the waters each year. and if the place were more readily accessible it would undoubtedly enjoy a large patronage.

In September, IgI2, Mr. N. M. Finkbiner, of the laboratory of the U. S. Geological Survey at Salem. Oregon, described 23 of the springs, and made field determinations of the temperature and alkalinity of each. He also collected from nine of these, from one cold spring, and from Breitenbush Creek above and below the springs, samples of water, which wereanalyzed conjointly at Salem by the writer, N. M. Finkbiner, and S. C. Dinsmore, state chemist of Nevada. The accompanying table gives results of both field and laboratory tests of these samples; the other 14 springs, field tests of which were made but are not reported. furnish water of similar character. or through these rocks would be heated, the bicarbonates in them would thereby be decomposed, and the waters would be relieved of part of their charge of iron, aluminum, alkaline earths, and carbonates. Alkaline salts with perhaps a slight residuum of calcium, and even less magnesium, would remain in solution. The calcic carbonate and the magnesia deposited would remain behind in the rock, and the water would move on without them. The carbonic acid set free as gas would react with rock silicates, decomposing them and depositing alkaline earth carbonates, the alkalies and part of the silica entering into solution. Thus a large part of the carbonic acid would be lost from the solution. The waters, percolating still further into the heated zone, would become further heated, and would be subjected to

Ayalyses of the Waters of Breitenbush Hot springs. ORegon

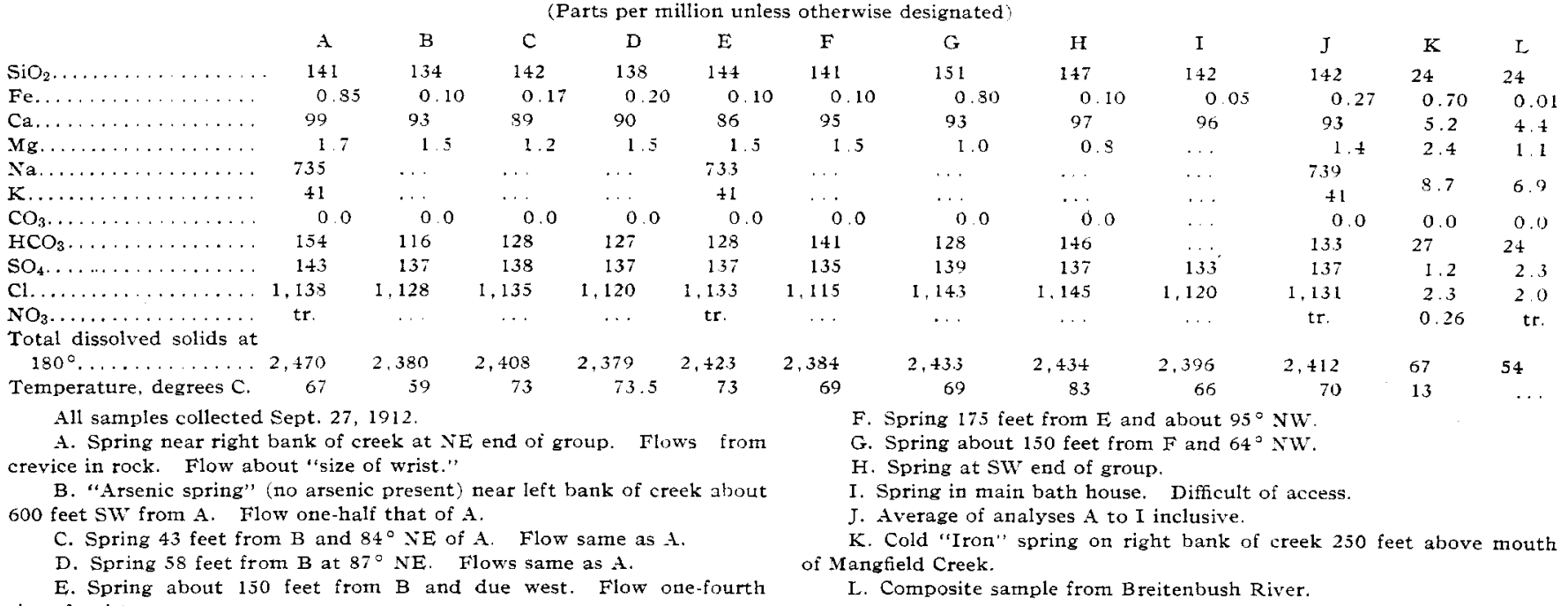
size of wrist.

The figures show that the several hot springs are merely separate outflows from a common source. The water is sodic chloride in character, but it contains small amounts of silica, calcium, bicarbonates. and sulfates. Minimum medicinal doses of both sulfates and carbonates might be obtained by drinking about 4 liters of the water, ${ }^{\prime}$ but the disagreeable and even nauseating taste of the chlorides would make the drinking of that amount in one day an Herculean feat. It is certain that any curative properties attributable to the mineral content are psychologic rather than physiologic.

The water is interesting to geologists, as it is an excellent example of a type encountered in many regions of recent volcanic activity. Hot springs in volcanic regions may be placed in several general divisions, such as sulfate springs, carbon dioxide, or "soda" springs, chloride springs, and the like. The origin of the waters of many of the types can easily be explained, but no adequate explanation of the presence of the large quantities of sodium chloride in the waters of the third type has yet been advanced, so far as known to the writer.

The lavas of the Cascade Range have been erupted

${ }^{1}$ Cf. R. B. Dole, "Concentration of Mineral Water in Relation to Therapeutic Activity," in Mineral Resources of the United States for 1911. L. S. Geol. Survey, 1912.

through, and now overlie, the older sedimentaries of the continental floor. At the great depth to which the sediments have been buried, the adjoining lava is still hot. This heat has also been communicated to some extent to the sediments so that these are at high temperatures. As any waters, percolating into increasingly great pressures. They would become more strongly concentrated, because of these and other physical conditions, and would finally be forced to the surface under combined static and thermal pressure. Any carbon dioxide still held in solution would cause small amounts of calcium, encountered en route, to be dissolved, and the springs would then deliver a sodic chloride, calcic bicarbonated and sulfated water, containing appreciable amounts of dissolved silica. This explanation avoids the necessity of considering the action of magnatic, or "juvenile" waters, and, being based entirely on well-known chemical reactions, has the merit of simplicity, and freedom from speculative hypotheses.

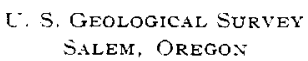

\section{PHOSPHATES IN SURFACE WATERS}

By GEORGE S. JAMIESON

Received February 5, 1913

The well-known colorimetric-molybdate method 
is not suitable for the estimation of phosphates in the majority of surface waters because it is only applicable to those free from color. I In order to apply the method to the analysis of soil extracts, Veitch ${ }^{2}$ removed, the color from the solutions by evaporating them to dryness with magnesium nitrate and igniting the residues until the organic matter was burned. In the colorimetric method of Schreiner and Brown, 3 which is based upon the precipitation of the phosphoric acid as ammonium magnesium phosphate, any color present is,removed when the precipitate is filtered and washed with ammonium hydroxide.

Recently it has been found that the coloring matter of a water can be destroyed by heating the residue, obtained by evaporation, with potassium permanganate and nitric acid. In order to test the accuracy of the method, known amounts of sodium phosphate were added to $50 \mathrm{cc}$. portions of a surface water which had a light brown color. Each solution was acidified with 2 cc. of nitric acid (sp.gr. r.07) and evaporated to dryness in porcelain dishes on the steam bath. The residue was moistened with $2 \mathrm{cc}$. of the diluted nitric acid and $0.5 \mathrm{cc}$. of a solution of potassium permanganate ( $\mathrm{r}$ gram per liter) was added. In the case of a highly colored water more permanganate should be added to insure complete decolorization. The solution was evaporated to dryness and the residue heated for an hour at $100^{\circ} \mathrm{C}$., then the residue was heated with $3 \mathrm{cc}$. of the same nitric acid and $\mathrm{I}_{5} \mathrm{cc}$. of silica-free distilled water. The evaporating dish was given a circular motion to facilitate the extraction of the phosphoric acid from the insoluble matter. After standing a short time the solution was transferred to a $50 \mathrm{cc}$. Nessler tube and the dish was washed several times with small quantities of distilled water. When it is necessary to filter the solutions, the filters should be tested, as it has been pointed out by several investigators that sometimes even the best quality of washed filters may contain enough silica to contribute considerable color when the ammonium molybdate is added. It was found that thorough washing of the filter paper with hot water removed the silica. The solutions in the Nessler tubes were diluted to the mark with silica-free distilled water, and $4 \mathrm{cc}$. of ammonium molybdate solution which contained I5 grams of the neutral salt per liter were added. The color was developed and compared with freshly prepared standard tubes. The following results were obtained:

$\begin{array}{cccc}\text { No. } & \text { Cc. of water } & \text { Mg. of } \mathrm{P}_{2} \mathrm{O}_{5} \text { added } & \mathrm{Mg} . \text { of } \mathrm{P}_{2} \mathrm{O}_{5} \text { found } \\ 1 & 50 & \ldots & 0.025 \\ 2 & 50 & \ldots & 0.025 \\ 3 & 50 & 0.050 & 0.075 \\ 4 & 50 & 0.050 & 0.075 \\ 5 & 50 & 0.040 & 0.065 \\ 6 & 50 & 0.100 & 0.126\end{array}$

Two experiments were made using potassium chlorate in place of potassium permanganate with the modification that several evaporations were made with nitric acid in order to remove the larger part of the chlorides

1 A. G. Woodman and L. L. Cayyan, J. Am. Chem. Soc, 23, 96 (1901).

2 Ibid., 25, 169 (1903).

3 Ibid., 26, 1463 (1904); also L. S. Dept. Agric,, Bur. of Soils, Bull. 31 $(1906)$. formed by the reduction of the chlorate. This method gave 0.025 milligram of $\mathrm{P}_{2} \mathrm{O}_{5}$ in duplicate, using 50 cc. portions of the water for analysis. The potassium permanganate is preferred not only on account of its rapidity as compared with the chlorate method, but also from the fact, which has been previously shown, ${ }^{\text {that }}$ low results are liable to be obtained with the latter method on account of the formation of aqua regia during the evaporations with nitric acid.

Phosphate determinations were made at various times upon several surface waters in the vicinity of New Haven, and it was observed that after a heavy or prolonged rain the amount of phosphate was considerably increased over the normal amount. It was further observed that the larger part of the phosphate was held in suspension as it could be removed by filtration. Three of the waters examined showed the normal amount of $\mathrm{P}_{2} \mathrm{O}_{5}$ to be about $0.6 \mathrm{milli}$ gram per liter. The average of 30 determinations (abnormally high results after rains being excluded) made upon different samples of water from a pond was 0.59 milligram of $\mathrm{P}_{2} \mathrm{O}_{5}$ per liter. In the following table, the results of several analyses are given of samples which were taken a day or two after heavy rains.

$\begin{array}{cc}\text { Water } & \mathrm{Mg} . \text { of } \mathrm{P}_{2} \mathrm{O}_{5} \text { per liter } \\ 1 \mathrm{~A} & 2.02 \\ 2 \mathrm{~A} & 1.05 \\ 3 \mathrm{~A} & 1.25 \\ 4 \mathrm{~A} & 1.35 \\ 5 \mathrm{~A} & 1.60 \\ 1 \mathrm{~B} & 1.35 \\ 2 \mathrm{~B} & 0.94 \\ 1 \mathrm{C} & 1.05 \\ 1 \mathrm{D} & 1.35 \\ 2 \mathrm{D} & 0.84\end{array}$

$\mathrm{Mg}$. of $\mathrm{P}_{2} \mathrm{O}_{5}$ per liter
in filtered water
$\ldots$
0.30
0.20
0.80
$\ldots$
$\ldots$
0.71
0.56
$\ldots$
0.56

It is believed that the larger part of the phosphates introduced into these waters by the rains was due in part to the cultivated fields and in part to the inhabited areas upon the water sheds. This investigation indicates that the determination of phosphates in surface waters may be of assistance in showing. pollution, and it is hoped that others more favorably situated may be able to investigate this problem thoroughly.

SHEFFIELD ChEMICAI LABORATORY

Yale University, New Haven, Cons

\section{THE DETERMINATION OF ZINC IN ORES}

BY D. J. DEMOREST

Received October 14, 1912

The following modification of Low's method has been worked out in order that it may be applicable. to any ore, no matter what impurities may be present. It depends upon the fact that ammonium carbonate completely separates zinc from iron, aluminum, manganese, lead and cadmium. The zinc (and copper), stay in solution as the zinc ammonia and copper ammonia carbonates. The copper is separated by hydrogen sulfide and the zinc is titrated by the well-known. ferrocyanide method.

The writer's experience coincides with that of Low, that neither lead nor aluminum are safe reagents to

\footnotetext{
${ }^{1}$ A. G. Woodman and L. L. Cayvan, J. Am. Chem. Soc., 23, 96 (1903)
} 